\title{
8 \\ The Spirit of Russian IT Capitalism
}

This chapter connects the analysis of the actors and their micro-level networks to the macro-level question of the nature of emerging Russian capitalism by asking what makes individuals commit themselves to working in the new Russian economy. The chapter will investigate the Russian IT business by comparing its moral aspects with the 'new spirit' of Western contemporary capitalism found by Luc Boltanski and Ève Chiapello ([1999], 2005) in their study of modern French business life. ${ }^{1}$

The main idea of this chapter is to see to what extent this new spirit, based on continuous networking and searching for new contacts and projects, are detectable in the most modern part of the Russian economy. The chapter presents first the basic ideas of Boltanski and Chiapello concerning this new spirit and then analyzes our Russian online survey data in order to find out if those data contain traces of it.

\section{The connexionist spirit of Western capitalism}

Boltanski's and Thévenot's justification theory presented in the previous chapter was criticized for, among other things, its allegedly ahistoric nature. In their book The New Spirit of Capitalism, Boltanski and Chiapello $(2005,2001)$ try to address the issue by examining capitalism from a historical perspective as a system that is not only constantly transforming itself, but also needs to get employees committed to participating in the system.

Boltanski and Chiapello focus on the dynamic relationship between capitalism and its critique, showing how capitalism has historically been able transform itself by adapting to the critique addressed to it. For example, while during the 1960s employees were lamenting loss of 
autonomy and increasing control, in the 1990s employees were required to be autonomous, and the control of employees was transferred to the customers (Boltanski and Chiapello 2005: 81).

To get employees committed to capitalism, something more than mere profit motive is needed. Capitalism has to stimulate participants through generating enthusiasm, offer security for them and their families, and be coherent with people's sense of justice by explaining how it contributes to the common good. By 'the spirit of capitalism' the authors refer precisely to the ideology justifying this commitment and making it attractive.

Boltanski and Chiapello distinguish three different spirits of capitalism, each of which corresponded with a particular form of the capital accumulation process. The first spirit depended mainly on domestic and market orders of worth. It corresponded with the traditional bourgeois capitalism which blossomed until the end of nineteenth century and was characterized mainly by small firms. The second spirit leaned more on the industrial and civic orders of worth and corresponded with the mode of capitalism which reigned from 1940-70 and was marked by managerial firms, big industrial companies, mass production and state economic policy. The third form has been emerging since 1980 and is characterized by network firms, Internet and biotech, global finance and varying and differentiated production (Chiapello and Fairclough 2002: 186-8, 191). Chiapello and Fairclough summarize this 'new spirit' in the following manner:

Life is conceived as a series of projects, the more they differ from one another, the more valuable they are. What is relevant is to be always pursuing some sort of activity, never to be without a project, without ideas, to be always looking forward to, and preparing for, something along with other persons, who are brought together by the drive for activity. When starting on a new project, all participants know that it will be short-lived. The perspective of an unavoidable and desirable end is built in the nature of the involvement, without curtailing the enthusiasm of the participants. Projects are well adapted to networking for the very reason that they are transitory forms: the succession of projects, by multiplying connections and increasing the number of ties, results in an expansion of networks.

(Chiapello and Fairclough 2002: 193)

This new 'connexionist' order of worth (cité) - as the six original orders of worth described in On Justification - is 'a model of justice, not an 
empirical description of the state of the world' (Boltanski and Chiapello 2005: 356). As other orders of worth, it consists of conventions that enable the establishing of equivalences that transcend the particularities of persons and things. On the basis of a common axiom, each order of worth proposes an architecture which specifies the qualities of the things that it contains, whether human beings or objects, and thus defines the contours of a corresponding 'world' (monde) (Boltanski and Chiapello 2005: 527). This model (cité connextionniste) is translated into English in The New Spirit of Capitalism as a 'projective city' and the corresponding world as a 'connexionist' or 'network' world. ${ }^{2}$

Unlike their counterparts in the 1960s, the workers of the new connexionist world are expected to put everything they have into their work, including emotions, personal relations and creativity. Worthiness or 'greatness' in this world means avoiding life-long projects. An ideal employee has distaste for stability, rootedness, and commitments to people, things or institutions:

[A]ccess to the condition of great man presupposes sacrificing anything that might impede availability - that is to say, the ability to engage in a new project. The great man renounces having a single project that lasts a lifetime (a vocation, a profession, a marriage, etc.). He is mobile. Nothing must hamper his movements. He is a 'nomad'.

(Boltanski and Chiapello 2005: 122)

These visionary leaders, coaches and experts are thus 'light' and mobile, renouncing stability and rootedness. They are capable of establishing and maintaining numerous diverse and enriching connections, and of extending networks. A truly great man (network extender) cannot, however, only serve his own selfish interest as a mere networker would do but has to think of the common good by being willing to help share his contacts and extend the networks:

The relations between great men and little people is just when, in exchange for the trust that the little people place in them and their zeal for engaging in projects, great men enhance the value of the more humble, in order to increase their employability - that is to say, their capacity, once one project is finished, to integrate themselves into another. Terminating a project without worrying about what becomes of those who have participated in it is unworthy of a great man.

(Boltanski and Chiapello 2005: 121) 
The crucial tests of greatness and network extending capabilities are the moments at the end of the project 'when people are in search of a new engagement, their ability to integrate themselves into a new project constituting one of the palpable signs of status. They have potential, know how to engage others, they are employable and also capable of employing others' (Boltanski and Chiapello 2005: 106, 112).

The exploitation in a network world is related to mobility differential: the great men are mobile, and exploit the local and stable nature of the small. At the same time, it is because of the local connections of the small that the great men can have success. The small men live in constant worry of being disconnected or abandoned by those who move around (Boltanski and Chiapello 2005: 364).

In the next section we turn to empirical analysis of our online survey data in search of the light and mobile network extenders in Russian IT business.

\section{The domestic spirit of Russian IT capitalism}

At first sight the IT industry would seem to be a perfect arena for the emerging new 'connexionist' spirit of Russian capitalism, since it is typically based on successive projects conducted by ambitious, welleducated managers and employees. Moreover, as has become clear in previous chapters, leaning on networks is an essential component of the new Russian economy. Could we thus find traces of the new network spirit in the Russian IT industry?

We searched for the answer through detailed examination of our online survey data on St. Petersburg IT professionals' personal networks. ${ }^{3}$ These data contain information on 72 respondents and their 343 network members. In the survey, the respondents were asked to name a maximum of six network members, three of whom had helped them to accomplish a successful project in 2003, and three others who had supported their career in IT (for a more detailed description, see Chapter 2).

For each supportive network member (e.g. colleague, boss, subordinate, client), the respondents were encouraged to record different kinds of information in our online survey questionnaire, such as a free-form qualitative description of the nature of the tie between the respondent and the network members (e.g. 'partner and a good friend', 'client and good acquaintance'), and the content of the help received from the network member (e.g. 'helped in leading the negotiations', 'invited me to work in big and interesting projects'). 
Because our data comes directly from IT professionals and not from business management guides as for Boltanski and Chiapello (2005), our results are not directly comparable. The nature of our data has to be distinguished from the texts of 'how to behave' management guides. However, studying Russian management guides probably would not have been a reliable method since many Russian IT managers do not have formal training in business management and were forced to learn everything by themselves or through imitating their more experienced colleagues. In all, our online survey produces interesting information about the possibly emerging new order among Russian managers in their own words in one of the most modern sectors of the Russian economy.

Since the survey was not originally planned to map the emerging moral orders of worth, it had some limitations. For example, the replies were often either too laconic or too general to give a precise idea of the order of worth in question. Despite this limitation, it seems reasonable to argue that if a new, connexionist spirit is about to be born in Russia, traces of it should be found in the Russian IT managers' reports of their networking activities connected to their ongoing projects or in their characterizations of the persons having supported these activities or their professional careers in general. These data seemed a good test case to see if a world populated by flexible Russian network extenders continuously in search of new connections and with a distaste for stability and rootedness was to emerge.

We analyzed both the qualitative descriptions concerning the contents of help received from network members and the nature of the network ties to find indications of an emerging connexionist order of worth based on projects and visionary team leaders, coaches, or project heads (Boltanski and Chiapello 2005: 79).

We thus examined all the qualitative descriptions reported by our Russian respondents concerning the contents of the help received to see if the help was related to searching out and extending network connections. However, most descriptions (43 percent) concerned the organizing and implementing of various work tasks (e.g. 'help in programming', 'helped to solve several difficult problems'). Sometimes these descriptions also contained moral evaluations explicitly valuing hard work and efficiency, thereby referring to the industrial order of worth ('Worked 16 hours without a break. Showed exceptional organizational capabilities', 'energetic approach to work, professionalism, capability to solve problems').

In only 17 cases (5 percent) of 343 instances of help or support was explicit reference made to a 'connexionist' type of activity (e.g. 'he 
found the first indispensable contact for the project', 'he introduced me to several people in the beginning of my career'). But under closer examination six cases out of these 17 concerned contact with 'useful people' (nuzhnye liudi) - a Russian expression for the closed circles of personal acquaintances needed to get things done. These instances of the data ("he recommended that I turn to a "useful person"' [porekomendoval obratit'sia k nuzhnomu cheloveku]) were thus rather part of the domestic world of personal dependencies than of the emerging new connexionist world.

Neither did the image of a charismatic and visionary team leader emerge in the descriptions of the contents of help. Though the personal networks clearly had a training and education function for the new Russian entrepreneurs, this happened rather through the moral category of mentoring. In the language of justification theory, mentoring is a 'domestic' category since it mostly implies a position in a system of mutual dependence. Mentoring was referred to, for example, through the forms of direct teaching or learning through following the example of a mentor. Thus, descriptions such as 'collaboration with him was my first "school" of working in IT', 'I learned from him', 'he taught me' and so forth, were noted in the data.

Mentors were sometimes described as generating enthusiasm and new ideas ('together we came up with many creative ideas which were implemented in the project') and as open-minded people who helped to find new ways of looking at things ('He taught me a non-standard approach to solving problems'). These descriptions were written with the vocabulary of curiosity, openness, and creativity, referring rather to the inspired than to the connexionist world.

More often, however, mentoring relationships implied a type of social tie similar to the relationship between master and apprentice (e.g. between the employer and employee, professor and student, or a newcomer in the field of IT and a more experienced colleague). The descriptions of mentors were often characterized as 'help' and expressed respect and filial liking extending far beyond the professional sphere of life.

The impression of the importance of moral evaluations in economic activities was further supported by the analysis of the nature of the relationships between our respondents and their network members. First, the respondents used a colorful, refined, and emotionally loaded vocabulary when assessing their professionally relevant ties. In addition to drug (friend), network members were also characterized as priiatel (pleasant acquaintance), tovarishch (buddy) or znakomyi (acquaintance), often 
preceded by an attribute detailing the emotional closeness between ego and alter (Lonkila 2006).

Second, though 41 percent of all network members were characterized solely in terms of their professional role ('colleague', 'client', 'subordinate'), 35 percent of the descriptions contained a mixture of the role-based and relation-based aspects of the tie, often combined with a moral assessment of the network member ('client and good friend', 'trustworthy subordinate, an open and frank workmate'). Moreover, 24 percent of the depictions characterized the tie only in terms of 'informal' aspects of the relationship, without any reference to the formal role ('good friend', 'good acquaintance', 'pleasant acquaintance').

Finally, strong ties, mainly friendship, accounted for 24 percent of all tie descriptions. This proportion of friendship relations, along with the long average duration of these ties, also lend credence to the conclusion that the 'distaste for stability and rootedness' of the connexionist world was very alien to our Russian respondents.

In general these results reinforce the image of the importance of moral evaluations in economic activities. Moreover, concluding from the analysis of the content and nature of the ties it is fair to suggest that the world populated by light and mobile nomads and governed by the new, connexionist spirit was not visible in our Russian data. Rather than placing general value on linking to others per se, Russian IT managers appreciated trusted links with specific individuals they knew personally or through someone.

More than anything, our results suggest that Russian IT capitalism seems rather to be animated by a 'domestic' spirit valuing the traditional and trusted ties of one's personal network. In the turmoil of the Russian transition, these ties create stability and a fixed reference point in an otherwise constantly changing society. 